\title{
Occupancy of Platelet Receptors for Platelet-activating Factor in Patients with Septicemia
}

Fernando Lopez Diez,* Maria Luisa Nieto, Sagrario Femandez-Gallardo, Miguel Angel Gijon, and Mariano Sanchez Crespo *Division of Intensive Medicine and Institute of Investigative Medicine, Fundacion Jimenez Diaz, CSIC-Associated Center, 28040-Madrid, Spain

\begin{abstract}
The possible involvement of platelet-activating factor (PAF) in the pathogenesis of endotoxemia, was investigated by using a binding assay to patients' platelets, complemented with the extraction and chemical characterization of PAF obtained from patients' platelets. Platelets from 12 human volunteers had $281 \pm 63$ freely accessible high affinity binding sites (PAF-receptors) per platelet; whereas this number was of $49 \pm 37$ PAFreceptors per platelet, $n=14$ samples, $P<0.01$, in a group of 13 patients with positive blood culture. A group of patients with respiratory or cardiovascular disturbances and negative blood culture had $253 \pm 74$, accessible receptors per platelet $(n$ $=19$ samples from 16 patients, $P<0.01$ as compared to septic patients, which was not significantly different when compared to control individuals). Patients with sepsis possessed signifcant amounts of PAF associated to their platelets, whereas this mediator could not be isolated from platelets of patients with respiratory or cardiovascular disturbances and negative blood culture, nor from platelets of control individuals. PAF was also assayed in whole blood samples and found at high concentrations in sepsis patients.

These data indicate that occupancy of PAF receptors in combination with high amounts of platelet-associated PAF, is a common finding in patients with sepsis.
\end{abstract}

\section{Introduction}

The pathogenesis of tissue injury following endotoxemia involves the recruitment of different inflammatory mediators and activation systems, e.g., coagulation and complement. As pointed out by Morrison and Ulevitch (1) it is in many cases the host response to the gram-negative organism, rather than the organism itself, which poses the ultimate threat to host tissues. At the present time, polymorphonuclear leukocytes, platelets, histamine, kinins, serotonin, arachidonate metabolites, cytokines, and complement-derived peptides have been implicated in the pathogenesis of the disturbances of cardiovascular, pulmonary, renal, digestive, and hematologic function observed during endotoxemia.

Recently, the role of platelets in the pathogenesis of the adult respiratory distress syndrome has been highlighted (re-

Address reprint requests to Dr. Sanchez Crespo, Laboratorio de Nefrologia, Fundacion Jimenez Diaz, Av. Reyes Catolicos 2, 28040 Madrid, Spain.

Received for publication 14 April 1988 and in revised form 21 November 1988.

J. Clin. Invest.

(C) The American Society for Clinical Investigation, Inc. 0021-9738/89/05/1733/08 \$2.00

Volume 83, May 1989, 1733-1740 viewed in reference 2); and platelet-activating factor (1-O-hexadecyl/octadecyl-2-acetyl-sn-glycero-3-phosphocholine) ${ }^{1}$ (3-5), a lipid autacoid with many biological actions, has been suggested as a mediator in endotoxin shock. This suggestion is based on the following evidence: $(a)$ infusion of exogenous PAF mimics the pathophysiology of the shock state in animals (6-8); (b) PAF is generated during experimental gram-negative sepsis (9-11); (c) several structurally different PAF antagonists have been reported to inhibit endotoxin-induced hypotension, lung injury and mortality (11-13); $(d)$ Beijer and co-workers (14) have recently shown that endotoxin-induced pulmonary platelet recruitment in the guinea pig is secondary to the release of PAF, but not to cyclooxygenase products of arachidonic acid. These findings suggest that PAF could play a role in tissue injury during endotoxemia, either through interactions with platelets or by acting on targets other than platelets. In fact, Heffner and co-workers have shown that PAF-stimulated human platelets cause pulmonary hypertension and edema in isolated rabbit lungs (15). In contrast, PAF-activated polymorphonuclear leukocytes were unable to cause lung damage in the same experimental model. Similar platelet-dependent pathways have been reported for the role of PAF on bronchoconstriction in the guinea pig (16), and in coronary artery vasodilatation in the canine (17).

In this paper we provide evidence as to the reduction of the number of freely accessible PAF-receptors on the platelet membrane in patients suffering from different types of septicemia. Many of these patients had also a reduced platelet count. In addition, a lipid substance analogous to PAF according to chemical and biological criteria could be eluted from the patients' platelets.

\section{Methods}

Patients. The diagnosis of sepsis was only considered after the documentation of at least one positive blood culture during the $48 \mathrm{~h}$ prior to the collection of blood for receptor assay. This diagnosis was also based on the history of the patient, physical examination, body temperature, peripheral leukocyte count, and differential white cell count, clinical course, results of cultures from other body sites, and the percentage of positive blood cultures (18). Septic shock was defined as the presence of sepsis accompanied by a sustained decrease in systolic blood pressure to less than $90 \mathrm{mmHg}$, or a drop of $40 \mathrm{mmHg}$ from base line, for at least $1 \mathrm{~h}$. Septic shock was diagnosed only if the preceding criteria were met, when volume replacement was adequate and the patient was taking no antihypertensive medication (19). The association of organ dysfunction was considered according to the parameters shown in Table I and the degree of severity expressed by the number of organs showing dysfunction. Standard clinical assessment of the patients included leukocyte count, hemostasis assay, analysis of the 20 parame-

1. Abbreviations used in this paper: $\mathrm{Fi}_{02}$, fraction of inspired oxygen; PAF, platelet-activating factor. 
Table I. Indicators of Organ Dysfunction in Septic Patients

\begin{tabular}{|c|c|}
\hline \multirow[t]{5}{*}{ Cardiovascular } & Bradycardia ( $<55$ beats $/ \mathrm{min})$ \\
\hline & Tachycardia ( $>90$ beats/min) \\
\hline & Systolic systemic arterial pressure $(<90 \mathrm{mmHg})$ \\
\hline & $\mathrm{pH}\left(<7.25\right.$ with arterial $\left.\mathrm{PCO}_{2}<50 \mathrm{mmHg}\right)$ \\
\hline & $\begin{array}{l}\text { Cardiac index }\left(<1.5 \mathrm{l} / \mathrm{min} \cdot \mathrm{m}^{2} \text { or }<1.8 \text { with }\right. \\
\text { inotropic agents) }\end{array}$ \\
\hline \multirow[t]{7}{*}{ Respiratory } & Bradypnea ( $<5$ breaths/min) \\
\hline & Tachypnea ( $>40$ breaths $/ \mathrm{min}$ ) \\
\hline & $\begin{array}{l}\text { Oxygen alveolar-arterial gradient }(>350 \mathrm{mmHg} \\
\left.\text { with } \mathrm{Fi}_{\mathrm{O} 2}=1\right)\end{array}$ \\
\hline & $\begin{array}{l}\text { Pulmonary shunt (Shunt flow/total cardiac output } \\
>0.20 \text { ) }\end{array}$ \\
\hline & Mechanical ventilatory assistance $(>72 \mathrm{~h}$ with \\
\hline & $\mathrm{Fi}_{\mathrm{O} 2}>0.6$ and positive expiratory end pressure) \\
\hline & $\mathrm{PCO}_{2}(>50 \mathrm{mmHg})$ \\
\hline \multirow[t]{3}{*}{ Renal } & Blood urea nitrogen $(>100 \mathrm{mg} / \mathrm{dl})$ \\
\hline & Creatinine (> $3 \mathrm{mg} / \mathrm{dl})$ \\
\hline & Oliguria $(<500 \mathrm{ml} / \mathrm{d}$ or $160 \mathrm{ml} / 8 \mathrm{~h})$ \\
\hline \multirow[t]{3}{*}{ Hepatic } & Bilirubin (> $3 \mathrm{mg} / \mathrm{dl})$ \\
\hline & $\begin{array}{l}\text { Alanine aminotransferase and LDH (doubled as } \\
\text { compared to patient's base line) }\end{array}$ \\
\hline & $\begin{array}{l}\text { Prolonged prothrombin time ( }>25 \% \text { not corrected } \\
\text { with vitamin } K \text { ) }\end{array}$ \\
\hline \multirow[t]{4}{*}{ Hematologic } & Abnormal leukocyte count $(<1,000 \mathrm{WBC} / \mu \mathrm{l})$ \\
\hline & Abnormal platelet count $(<20,000$ platelets $/ \mu \mathrm{l})$ \\
\hline & Anemia (hematocrit $<20 \%$ ) \\
\hline & Disseminated intravascular coagulation \\
\hline $\begin{array}{l}\text { Nervous } \\
\text { system }\end{array}$ & Glasgow score coma $<6$ \\
\hline Metabolic & Nitrogen losses $>15 \mathrm{~g} / \mathrm{d}$ \\
\hline \multirow[t]{2}{*}{ Digestive } & Post operative acalculous cholecystitis \\
\hline & Acute lesions in the gastric mucosa \\
\hline
\end{tabular}

ters of blood biochemistry of SMAC 20 autoanalyzer (Technicon Instruments Corp., Tarrytown, NY), chest x-ray and Swan-Ganz catheterization in patients with evidence of shock. A group of patients for comparison included patients with local infections without positive blood culture, cardiogenic shock from acute myocardial infarction, angina pectoris, pancreatitis, abdominal surgery, and antimony intoxication by overdose of pentavalent antimonials in a patient with visceral leishmaniasis. All these patients were at the time of study admitted to Intensive Care Unit as a consequence of their clinical condition, and were thereby considered as the control group most close to septic patients. Antibiotic treatment at the time of study was not discontinued for ethical reasons. A group of age-matched staff members were considered as normal controls.

Platelet isolation. Freshly drawn blood samples of $20 \mathrm{ml}$ were collected in citric acid-dextrose solution as described by Kloprogge and Akkerman (20). In the case of healthy volunteers, the donors claimed not to have taken any drugs during the previous $10 \mathrm{~d}$ and had been fasting for the last $10 \mathrm{~h}$ before blood collection. After centrifugation at $200 \mathrm{~g},\left(10 \mathrm{~min}\right.$ at $\left.20^{\circ} \mathrm{C}\right)$, platelet-rich plasma was placed onto a Sepharose 2B (Pharmacia Fine Chemicals, Uppsala, Sweden) column equilibrated with $\mathrm{Ca}^{2+}$-free Tyrode's solution, $\mathrm{pH} 7.25$, supplemented with $0.2 \%$ BSA and $5 \mathrm{mM}$ glucose. After elution, platelets were counted, adjusted to $2 \times 10^{8}$ cells $/ \mathrm{ml}$ in Tyrode's solution and used for binding assays.

Binding studies with $\left[{ }^{3} H\right] P A F$. Gel-filtered platelets were incubated with different concentrations of $\left[{ }^{3} \mathrm{H}\right] \mathrm{PAF}$ (1-O- $\left[{ }^{3} \mathrm{H}\right]$ hexadecyl-2acetyl-sn-glycero-3-phosphocholine, $81 \mathrm{Ci} / \mathrm{mmol}$ sp act, was from
Amersham International, Bucks, UK). The purity of the ligand was checked by HPLC for each batch, and only those batches showing $>97 \%$ purity were used for binding studies. The assay was carried out as described by Kloprogge and Akkerman (20). Under these conditions, aggregation and secretion were prevented due to the absence of stirring, the absence of fibrinogen and the use of concentrations of [ $\left.{ }^{3} \mathrm{H}\right]$ PAF of $0.12-1.2 \mathrm{nM}$, i.e., below $10 \mathrm{nM}$, which is the threshold for optical aggregation and secretion under optimal conditions. The studies were carried out at room temperature and the specific activity of $\left[{ }^{3} \mathrm{H}\right]$ PAF was kept constant at all concentrations. The reaction was carried out in a volume of $0.5 \mathrm{ml}$ in Eppendorf microcentrifuge tubes. Nonspecific binding was measured for each concentration of $\left[{ }^{3} \mathrm{H}\right] \mathrm{PAF}$ by adding an 80-fold molar excess of nonlabeled PAF (hexadecyl, from Bachem Feinchemikalien, Bubendorf, Switzerland). This concentration of unlabeled PAF was selected, after testing the effect of a range of 40 to 500 -fold molar concentrations, to avoid the threshold for aggregation as much as possible.

After the cells had been incubated for $45 \mathrm{~min}$, except when otherwise indicated, the reaction was stopped by adding cold Tyrode's medium and the platelets isolated by centrifugation in an Eppendorf microcentrifuge $(8,000 \mathrm{rpm}, 30 \mathrm{~s})$, followed by washing three times with the same medium. Cell pellets were resuspended in $1 \%$ Triton $\mathrm{X}-100$ in $5 \% \mathrm{HNO}_{3}$ and transferred into containers with a scintillation solution for aqueous samples. $\left[{ }^{3} \mathrm{H}\right] \mathrm{PAF}$ trapping due to nonselective trapping of extracellular medium was found to be $<0.2 \%$ by including $\left[{ }^{14} \mathrm{C}\right]$ inulin as an extracellular space marker. Binding data were represented as a Scatchard plot (21) and the value of $K_{\mathrm{D}}$ and the number of high affinity binding sites determined by using the program EBDA from Elsevier-Biosoft, Cambridge, UK, in a PC compatible computer.

$\left[{ }^{3} \mathrm{H}\right]$ Phospholipid analysis. To assess whether $\left[{ }^{3} \mathrm{H}\right] \mathrm{PAF}$ was converted to other compounds, in some experiments, the incubation of gel-filtered platelets with $\left[{ }^{3} \mathrm{H}\right] \mathrm{PAF}$ was terminated by Bligh and Dyer extraction using methanol supplemented with $2 \%$ acetic acid (22). After formation of a bilayer by addition of chloroform and water, the chloroform layer was collected, evaporated to dryness under $\mathrm{N}_{2}$ stream and the lipid residue subjected to TLC using as developer: propionic acid/propanol/chloroform/water (50:25:8:6, vol/vol). The areas migrating as standards of 1-O-alkyl-2-acetyl-sn-glycero-3-phosphocholine (PAF), 1-O-alkyl-2-lyso-sn-glycero-3-phosphocholine (lyso-PAF) and 1-O-alkyl-2-acyl-sn-glycero-3-phosphocholine were scraped off and the radioactivity measured by scintillation spectrometry. Further characterization of the lipid material extracted from platelets was performed by reverse-phase HPLC as described below.

Bioassay and characterization of PAF. Gel-filtered platelets from both healthy donors and patients were washed twice in cold saline solution, containing $1 \mathrm{mM}$ EDTA, $\mathrm{pH} 7.2$, at $1,000 \mathrm{~g}\left(10 \mathrm{~min}\right.$ at $\left.4^{\circ} \mathrm{C}\right)$, and the resulting platelet pellet was then subjected to Bligh and Dyer extraction. This procedure did not stimulate platelets to generate PAF, nor did it cause the catabolism of exogenously added $\left[{ }^{3} \mathrm{H}\right] \mathrm{PAF}$. The chloroform layer was removed, and the aqueous phase was treated three times with methanol/chloroform $(1: 1$, vol/vol) with vigorous vortexing to achieve complete extraction of phospholipids. Recovery of PAF through the extraction was $>95 \%$ as determined by radiotracer studies. The pooled chloroform extracts were evaporated to dryness under $\mathrm{N}_{2}$ stream and resuspended in $100 \mu \mathrm{l}$ of methanol for straightphase HPLC. Fractions eluting with a retention time of 32-36 min, were pooled, evaporated to dryness and resuspended in a Hepes-buffered medium supplemented with $0.25 \%$ BSA and tested for plateletsecreting activity on washed rabbit platelets labeled with $\left[{ }^{3} \mathrm{H}\right]$ serotonin as described in reference 23. For quantitation of PAF, a standard curve was constructed with synthetic PAF (hexadecyl) and the platelet-secreting activity expressed as nanogram equivalents of PAF. The characterization of the platelet-secreting activity as PAF was based on its HPLC retention time, sensitivity of the biological activity to previous treatment with phospholipases $A_{2}$ and $C$, resistance to the treatment by phospholipase $A_{1}$ and blockade of the platelet-secreting ability by $B N$ 52021 (IHB-Research Laboratories, Le Plessis Robinson, France), a specific PAF-receptor antagonist $(24,25)$. When whole blood samples 
were used as starting material for the PAF assay, a TLC step was included before HPLC, as described in reference 24 .

High-performance liquid chromatography analysis. Straight-phase HPLC was carried out using a dual-pump Kontron system (model 420 Kontron Instruments, Zurich, Switzerland), fitted with a silica Spheri5 column $(220 \times 4.6 \mathrm{~mm}, 5 \mu \mathrm{m})$, and a $15 \times 4.6 \mathrm{~mm}$ precolumn, using as system of solvents $B[96 \%$ isopropanol/hexane, $1: 1$, supplemented with $0.005 \%$ acetic acid] and $A[4 \%$ water] eluted linearly to $8 \%$ during a 15-min period (26). The column run lasted for $60 \mathrm{~min}$ and $1-\mathrm{ml}$ fractions were collected. The system was equipped with a Uvikon 735LC variable wavelength detector from Kontron Instruments, which was operated at $206 \mathrm{~nm}$. The separation of individual molecular species of PAF was carried out using a Spheri-5 RP-18 $(220 \times 4.6 \mathrm{~mm}$, $5 \mu \mathrm{m}$ ) column from Brownlee Laboratories (Santa Clara, CA) and a 15 $\times 4.6 \mathrm{~mm}$ precolumn. The mobile phase was a modification of the method of Patton (27) as described by Jackson and co-workers (28) and consisted of methanol/water/acetonitrile; 85:10:5 (vol/vol) that contained $20 \mathrm{mM}$ choline chloride. Samples were dissolved in methanol and loaded on the column with a 200- $\mu$ l loop using a Rheodyne 7125 injector (Rheodyne Inc., Cotati, CA). The column was eluted at 1 $\mathrm{ml} / \mathrm{min}$ during a 60 -min period followed by an additional period of 60 $\mathrm{min}$ in which the mobile phase was methanol/water/acetonitrile, 90:7:2.5 (vol/vol). Fractions collected during the initial $60 \mathrm{~min}$ were treated with $1 \mathrm{ml}$ of chloroform and water to allow bilayer formation, and the lower phase collected, evaporated to dryness, resuspended in a Hepes-buffered medium supplemented with $0.25 \%$ BSA, and used for the bioassay.

Statistics. Data were expressed as the mean \pm SD. For the comparison of more than two groups of data, one-way analysis of variance (ANOVA) was used after samples were found to be normally distributed. For comparison of two groups of samples not normally distributed, the Mann-Whitney $U$ test was used. Linear correlations were calculated using standard methods. Statistical procedures were performed using a data base and statistical package (Sigma, Horus Hardware Co., Madrid, Spain). Differences were considered significant at $P$ $<0.05$.

\section{Results}

Binding studies. Platelets from normal volunteers bound $\left[{ }^{3} \mathrm{H}\right] \mathrm{PAF}$ in a time-dependent manner (Fig. 1). Because this binding was maximal after $30 \mathrm{~min}$ and remained stable over the period of incubation (up to $90 \mathrm{~min}$ ) in three independent experiments, an incubation period of $45 \mathrm{~min}$ was selected for steady-state binding studies. When the experiments were per-

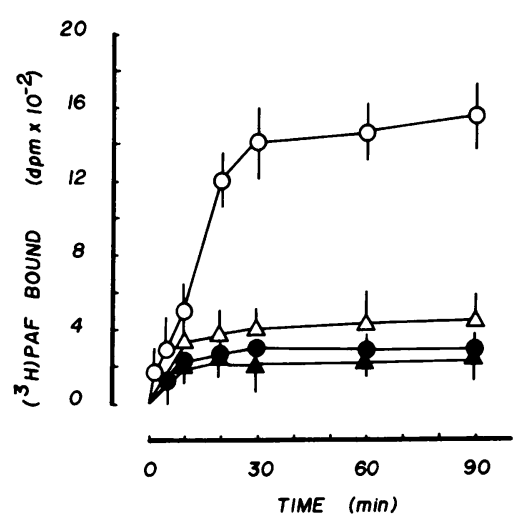

Figure 1. Time course of $\left[{ }^{3} \mathrm{H}\right]$ PAF binding to human platelets and inhibition by BN 52021 . $10^{8}$ platelets from normal volunteers were incubated in a volume of $0.5 \mathrm{ml}$ at room temperature with $0.12 \mathrm{nM}$ $\left[{ }^{3} \mathrm{H}\right] \mathrm{PAF}$ in the presence of vehicle (circles) or $10 \mu \mathrm{M}$ BN 52021 (triangles). At the times indicated samples were taken and the radioactivity associated to the platelet pellet determined by scintillation spectrometry. Nonspecific binding was determined by incubation in the presence of a 80-fold molar excess of nonlabeled PAF. Open symbols indicate total binding. Closed symbols indicate nonspecific binding. Data represent mean $\pm \mathrm{SD}$ of three independent experiments. formed in the presence of $10 \mu \mathrm{M}$ BN 52021, a PAF-receptor antagonist, specific binding (calculated by subtracting nonspecific binding from total binding) was reduced by $85 \%$, whereas nonspecific binding was not significantly influenced (Fig. 1). In order to assess the dissociation rate of $\left[{ }^{3} \mathrm{H}\right] \mathrm{PAF}$ a 80 -fold molar excess of unlabeled PAF was added after $45 \mathrm{~min}$ of incubation in the presence of $\left[{ }^{3} \mathrm{H}\right] \mathrm{PAF}$ (time 0 in Fig. 2). At different times thereafter, samples were taken and the radioactivity associated to the platelet pellet assessed. As shown in Fig. 2 , which summarizes three independent experiments, total binding at time 0 was $1,810 \pm 190 \mathrm{dpm}$, whereas it was reduced to $1,180 \pm 330 \mathrm{dpm}$ after $15 \mathrm{~min}$ of incubation in the presence of unlabeled PAF. This indicates that a fraction of the $\left[{ }^{3} \mathrm{H}\right]$ PAF bound to human platelets is still dissociable with unlabeled PAF after these periods of incubation. Taken together the preceding data were considered as an evidence of the occurrence of $\left[{ }^{3} \mathrm{H}\right] \mathrm{PAF}$ binding to specific receptors. The binding of $\left[{ }^{3} \mathrm{H}\right] \mathrm{PAF}$ by platelets from 12 normal volunteers in steadystate conditions was represented by plotting the ratio bound/ free PAF versus bound [ $\left.{ }^{3} \mathrm{H}\right] \mathrm{PAF}$. A $K_{\mathrm{D}}$ value of $0.23 \pm 0.05 \mathrm{nM}$ was found; and the number of accessible high affinity binding sites (PAF-receptors) ranged from 184 to 387 per platelet $(281 \pm 63, n=12)$. To assess the metabolic fate of bound $\left[{ }^{3} \mathrm{H}\right]-$ PAF, the incubation of platelets and ligand was stopped at different times by Bligh and Dyer extraction, followed by TLC and HPLC. Binding of $\left[{ }^{3} \mathrm{H}\right] \mathrm{PAF}$ was not followed by significant deacetylation-reacylation, since $\sim 97 \%$ of the label migrated as PAF even after a period of incubation of $90 \mathrm{~min}$ (Fig. 3).

Platelets from sepsis patients bound less $\left[{ }^{3} \mathrm{H}\right] \mathrm{PAF}$ than those from normal volunteers; but their binding showed a time course similar to that found in platelets from normal volunteers, and specific binding could be blocked by BN 52021 (Fig. 4). Addition of unlabeled PAF after a 45-min period of incubation with $\left[{ }^{3} \mathrm{H}\right] \mathrm{PAF}$, followed by an additional incubation period of 15 min showed that platelets still retained a $75 \%$ of total binding (Fig. 5). From these findings it was concluded that platelets from sepsis patients interacted with PAF in a manner similar to that observed in normal volunteers. As shown in Table II, platelets from patients with positive blood cultures showed a number of 0-115 freely accessible PAF receptors per platelet $(49 \pm 37, n=14$ samples from 13 patients), as compared to both normal volunteers $(281 \pm 63, n=12, P$ $<0.01)$ and to the group of patients with cardiovascular or

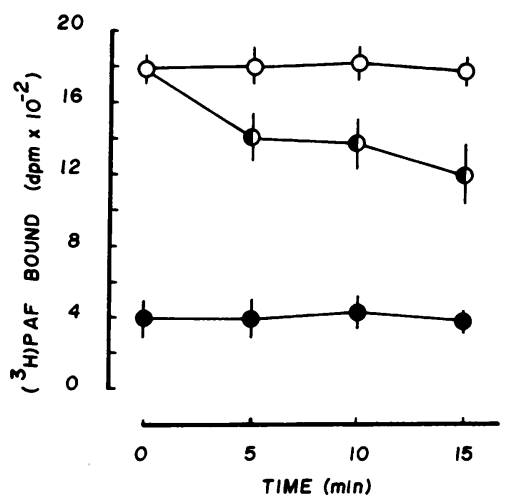

Figure 2. Reversibility of $\left[{ }^{3} \mathrm{H}\right] \mathrm{PAF}$ binding to platelets from normal volunteers. Platelets were incubated at room temperature for $45 \mathrm{~min}$ under the conditions described in the legend to Fig. 1. At time 0 , tubes containing only $\left[{ }^{3} \mathrm{H}\right] \mathrm{PAF}$ were divided into two sets. One received an 80 -fold molar excess of unlabeled PAF (o), and the other one received no addition (0). At the times indicated incubation was stopped and binding to platelets assessed. Data represent mean \pm SD of three independent experiments. 


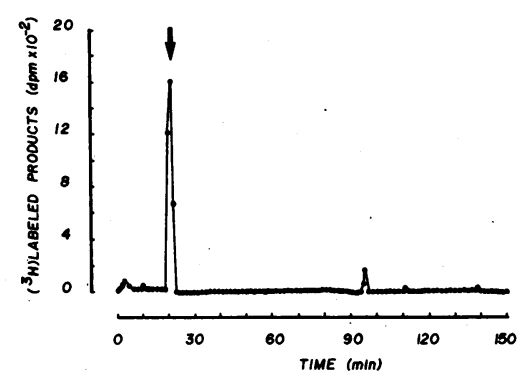

dryness and resuspended in $200 \mu$ l of methan HPLC. At $60 \mathrm{~min}$, the composition of the mobile phase was changed to favor the elution of alkyl-acyl molecular species. Radioactivity was assessed in the different fractions. Recovery of the radioactivity added to platelets was $97 \%$. The arrow indicates the retention time of a $\left[{ }^{3} \mathrm{H}\right] \mathrm{PAF}$ standard.

respiratory disturbances and negative blood cultures (range 84-390 receptors per platelet, $253 \pm 74, n=19$ samples from 16 patients, $P<0.01$ ) (Table III). In contrast, there was no difference in the number of accessible PAF-receptors between nonseptic patients and normal controls. $K_{\mathrm{D}}$ value in septic patients was $0.21 \pm 0.08 \mathrm{nM}$, i.e., similar to that found in normal volunteers (Fig. 6). Patients with the lowest number of accessible binding sites to exogenous radiolabeled $\left[{ }^{3} \mathrm{H}\right] \mathrm{PAF}$, usually showed a reduced platelet count, however, both parameters showed a poor correlation $(r=0.3372, P>0.1)$. Three patients could be followed for a period of several days, and blood samples taken at different intervals. In a patient with aortic valvular disease and Staphylococcus aureus infection, a reduced number of accessible high affinity binding sites preceded the appearance of spleen septic infarctions and the demonstration of a new positive blood culture. This was followed by clinical recovery and negative blood cultures, which were accompanied by the presence on patients' platelets of a number of accessible PAF-receptors analogous to those of normal controls. Another patient with a positive blood culture (Staphylococcus epidermidis related to colonization of a venous catheter), showed an increase of accessible high affinity binding sites from 115 to 182 per platelet $1 \mathrm{~d}$ after catheter removal. Finally, a patient with meningeal infection showed an increase of accessible receptors after surgery. No differences were observed in the number of accessible receptors related to infection with either gram-positive (Staphylococcus epidermidis and Staphylococcus aureus) or gram-negative septicemia (Bacteroides, Escherichia coli, Pseudomonas, Klebsiella, Enterobacter, and Salmonella). Furthermore, a patient with a positive blood culture for Candida and respiratory failure only

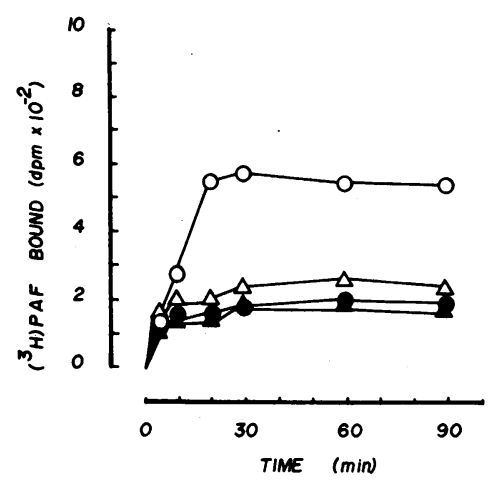

Figure 4. Time course of $\left[{ }^{3} \mathrm{H}\right] \mathrm{PAF}$ binding to platelets from a sepsis patient and inhibition by BN 52021 . Symbols and legend are as in Fig. 1.

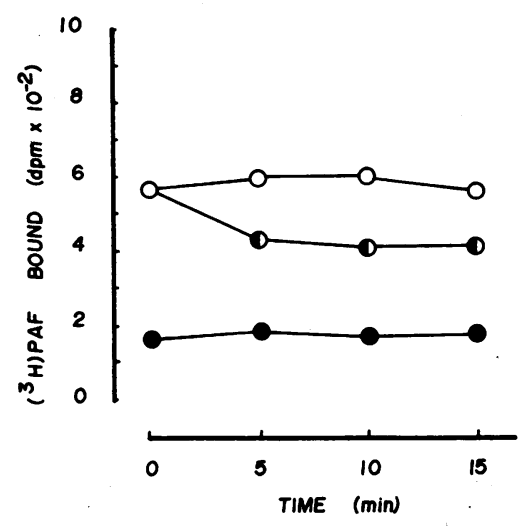

Figure 5. Reversibility of $\left[{ }^{3} \mathrm{H}\right] \mathrm{PAF}$ binding to platelets from a sepsis patient. Symbols and legend are as in Fig. 2.

had 78 accessible receptors per platelet. The platelet counts showed no differences $(P<0.1)$ between 13 samples from 12 septic patients $(170,384 \pm 131,551$ platelets $/ \mu \mathrm{l})$ and 19 samples from 16 patients with respiratory or cardiovascular disturbances and negative blood culture $(234,000 \pm 115,172$ platelets/ $\mu \mathrm{l})$. During the period of study, 9 of 13 septic patients died, which impeded repetition of the study after blood culture became negative, and three additional patients could not be included in the study because of a reduced platelet count, which made it impossible to obtain an appropriate number of platelets for binding assays. In contrast, only 4 of 13 patients from the nonseptic group died during the period of study.

$P A F$ assay and characterization. The lack of accessible high affinity binding sites on the platelet surface of patients with positive blood cultures was accompanied by the elution from platelets of a lipid compound analogous to PAF (Table II). This substance was eluted following Bligh and Dyer extraction and after recovery from the chloroform layer and preparation for HPLC, showed a retention time of $34 \mathrm{~min}$ in straight-phase HPLC, and of $21 \mathrm{~min}$ in reverse-phase HPLC, i.e., analogous to those of a standard of hexadecyl $\left[{ }^{3} \mathrm{H}\right] \mathrm{PAF}$ (Fig. 7). PAF activity was not coincident with any of the peaks detected by ultraviolet absorbance, nor was it detected at longer retention times in reverse-phase HPLC, i.e., those of the octadecyl species of PAF. This HPLC purification procedure improved the quantitation of the activity, as compared to the results obtained in samples only treated by TLC. The latter samples showed a reduced platelet-activating activity, which in some cases increased when the sample was diluted in HepesBSA medium. This is most probably due to the removal of PAF inhibitors (see below). PAF could not be detected on either 11 samples of platelets from 9 nonseptic patients with cardiovascular or respiratory disturbances nor on platelets from 8 normal volunteers (Table III). Blood PAF levels in seven sepsis patients whose individual values are shown in Table II, were $0.7 \pm 0.2 \mathrm{ng} / \mathrm{ml}$. Interestingly, in the three patients whose whole blood samples were processed in parallel, most PAF appeared linked to platelets, whereas normal volunteers showed small amounts of assayable PAF in whole blood $(0.17 \pm 0.03 \mathrm{ng} / \mathrm{ml}, n=17, P<0.01$ as compared to sepsis patients), and undetectable amounts associated to platelets.

\section{Discussion}

This study shows a reduced number of freely accessible PAF receptors on platelets from patients with sepsis and the separa- 
Table II. Clinical Data of Patients with Positive Blood Culture

\begin{tabular}{|c|c|c|c|c|c|c|c|c|}
\hline Age & Sex & Focus & Bacteria & O.D. & P.C. & A.R. & P-PAF & B-PAF \\
\hline 65 & $F$ & Lung & Enterobacter & 2 & 148,000 & 44 & & 0.6 \\
\hline \multirow[t]{4}{*}{41} & $\mathbf{M}$ & Aortic valve & S. aureus & 5 & 74,000 & 66 & 1.11 & 0.7 \\
\hline & & & - $^{*}$ & 4 & 116,000 & 91 & & \\
\hline & & & S. aureus & 5 & 525,000 & 78 & & 0.7 \\
\hline & & & - $^{*}$ & 0 & 263,000 & 246 & & \\
\hline 70 & $\mathbf{M}$ & Peritoneum & Bacteroides & 2 & N.D. & 30 & & 0.6 \\
\hline \multirow[t]{2}{*}{51} & $F$ & Colostomy & S. epiderm. & 0 & 280,000 & 115 & & \\
\hline & & Catheter & - & 0 & 248,000 & 182 & & \\
\hline 65 & $\mathbf{F}$ & Mitral valve & S. enteridi. & 3 & 118,000 & 60 & & 0.6 \\
\hline 52 & $\mathbf{M}$ & Lung & Enterobacter & 0 & 256,000 & 108 & 1.01 & 1.4 \\
\hline 61 & $\mathbf{M}$ & Peritoneum & Bacteroides & 4 & 26,000 & 0 & 1.66 & 0.6 \\
\hline 54 & $\mathbf{M}$ & Peritoneum & Enterobacter & 3 & 19,000 & 0 & 2.12 & \\
\hline 24 & $\mathbf{F}$ & Uterus & Candida & 1 & 190,000 & 78 & 0.08 & \\
\hline 61 & $\mathbf{M}$ & Abdomen & E. coli & 3 & 105,000 & 54 & 0.02 & \\
\hline 82 & $\mathrm{~F}$ & Gut & E. coli \& Bacteroides & 5 & 139,000 & 32 & & \\
\hline 82 & $\mathbf{M}$ & Lung & Pseudomonas & 3 & 185,000 & 27 & & \\
\hline \multirow[t]{2}{*}{60} & $\mathrm{~F}$ & Meninges & Klebsiella & 4 & 150,000 & 0 & & \\
\hline & & & - & 0 & 320,000 & 271 & & \\
\hline
\end{tabular}

* Patients at this stage were not considered to be septic patients, and their data have been included for statistics in the group of hemodynamic disturbances without sepsis. O.D., the number of organs with dysfunction. P.C., the nearest peripheral platelet count (platelets/ $\mu$ l); A.R., the number of accessible receptors; P-PAF means platelet-associated PAF $\left(\mathrm{ng} / 10^{8}\right.$ platelets); B-PAF means $\mathrm{ng} / \mathrm{ml}$ of PAF contained in a blood sample extracted and processed as in reference 24 .

tion from these cells of a lipid substance with platelet-activating properties analogous to hexadecyl PAF. Both findings may indicate that platelets from patients with septicemia had reacted with endogenous PAF and this had caused downregulation of the receptors and an enhanced internalization of PAF or even trapping of PAF into another compartment. Although PMN possess membrane receptors (29), the possible interac-

Table III. Clinical Data of Patients with Respiratory or Cardiovascular Disturbances and Negative Blood Culture

\begin{tabular}{lllcrc}
\hline Age & Sex & \multicolumn{1}{c}{ Diagnosis } & Shock & P.C. & A.R. \\
\hline 56 & M & Leishmaniasis & + & 153,000 & $295^{*}$ \\
50 & M & AMI & + & 187,000 & 84 \\
46 & M & Angina & - & 245,000 & $390^{*}$ \\
45 & M & Mediastinitis & - & 145,000 & $300^{*}$ \\
65 & M & Prostatectomy & + & 61,000 & $230^{*}$ \\
& & & - & 150,000 & $250^{*}$ \\
26 & F & Septic abortion & - & 118,000 & $318^{*}$ \\
65 & F & AMI & + & 340,000 & $325^{*}$ \\
& & & + & 320,000 & 290 \\
74 & M & Abdominal aorta aneurysm & - & 369,000 & $246^{*}$ \\
42 & M & Pneumonia & - & 531,000 & $252^{*}$ \\
53 & M & Pancreatitis & + & 299,000 & 246 \\
68 & F & Pneumonia & - & 205,000 & $262^{*}$ \\
75 & F & Colonic diverticulitis & - & 102,000 & $212^{*}$ \\
65 & M & Pancreatitis & - & 274,000 & 319 \\
& & & & &
\end{tabular}

* PAF eluted from platelets was undetectable; P.C., platelet count (platelets/ $\mu$ l blood); A.R., number of accessible receptors; AMI, acute myocardial infarction. tion of PAF with leukocytes has not been addressed. This has been due to several reasons. First, there is a higher number of peripheral platelets than PMN, and in many cases it is difficult to obtain PMN without platelet contamination; second, isolation of PMN needs more steps than platelet isolation and includes exposure to Dextran, Ficoll-Hypaque, ammonium

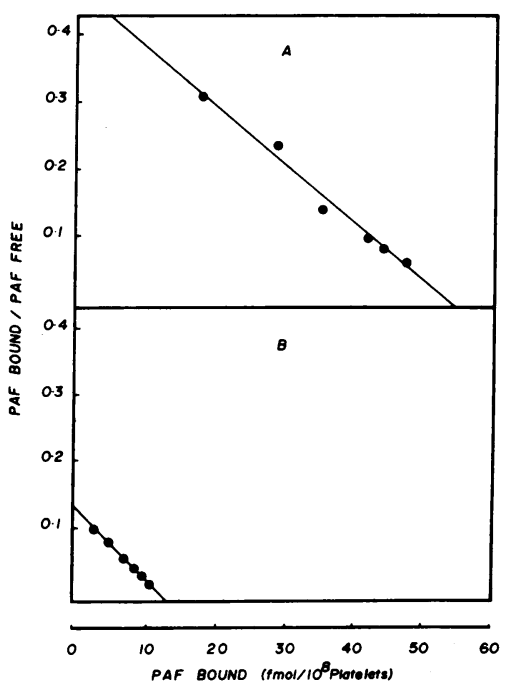

Figure 6. Scatchard plot of the specific binding of $\left[{ }^{3} \mathrm{H}\right] \mathrm{PAF}$ to gel-filtered platelets from a control individual $(A)$ and from a sepsis patient $(B)$. Gel-filtered human platelets at a concentration of $10^{8} / 0.5 \mathrm{ml}$ were incubated in the presence of different concentrations of $\left[{ }^{3} \mathrm{H}\right] \mathrm{PAF}(0.12-1.2$ $\mathrm{nM}$ ) for $45 \mathrm{~min}$. At the end of this period the incubation was stopped by adding cold medium and centrifugation at $8,000 \mathrm{rpm}$ for $30 \mathrm{~s}$. Nonspecific binding was determined by incubating platelets under the same conditions in the presence of a 80fold molar excess of unlabeled ligand. Radioactivity was assessed in both cell pellets and supernatants and data plotted after subtraction of nonspecific binding at each point. Each point represents mean values of triplicate samples. The number of accessible binding sites is 331 per platelet in $\mathrm{A}$, and 78 per platelet in $\mathrm{B}$. 


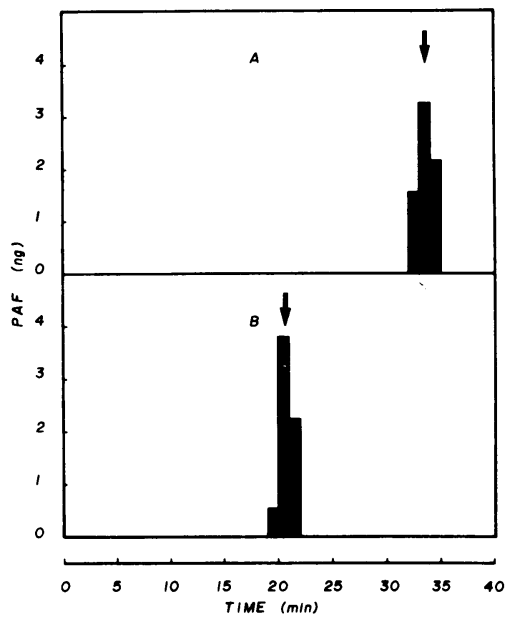

Figure 7. HPLC behavior of PAF eluted from platelets. Platelets from a sepsis patient were washed in saline solution after being eluted from Sepharose 2B column, and then lipids were extracted by Bligh and Dyer procedure The chloroform extract was divided into two halves and evaporated to dryness. One of them was resuspended in isopropanol/hexane for straight-phase HPLC $(A)$, and the other one in methanol for reverse-

phase HPLC $(B)$. PAF was bioassayed in the different fractions and quantitated in nanograms. The arrows indicate the retention time of $\left[{ }^{3} \mathrm{H}\right] \mathrm{PAF}$ (hexadecyl) standards.

chloride, or hyposmotic media. Furthermore, PMN rapidly metabolize PAF to alkyl-acyl-glycero-phosphocholine.

The demonstration of the involvement of PAF in septicemia has been suggested by a number of previous observations on the presence of high amounts of PAF in biological fluids from patients and experimental animals with different conditions. In fact, high amounts of PAF have been described in blood from rabbits with both systemic anaphylaxis (30) and serum sickness (31); in blood, liver, and spleen of mice challenged with soluble aggregates of immunoglobulin $G(32)$; in blood from rats with experimental cirrhosis of the liver and hemodynamic impairment (33); as well as in blood, peritoneal exudate, and spleen and lung tissue of rats with endotoxemia (9-11). In human diseases, high amounts of blood PAF have only been described in patients with cold urticaria upon challenge by immersion of the arm in an ice bath (34) and in patients with severe cirrhosis of the liver and hemodynamic disturbances (35).

The assay of PAF in complex biological fluids such as blood and urine (36) has many difficulties related to the processing of samples and coextraction of other lipids that inhibit PAF action on platelets and, accordingly, interfere with the bioassay. This was already pointed out in an early paper by Pinckard and co-workers (30), and has recently been addressed by Miwa and co-workers (37), who described lipid materials that masked the demonstration of PAF in the liver of rats. More recently, Nakayama and co-workers (38) have reported the presence in the rat uterus of two endogenous inhibitors of PAF. Inhibitor I was characterized as a mixture of 1-acyl- and 1-alkyl-2-lyso-sn-glycero-3-phosphocholine, and Inhibitor II was defined as a mixture of $N$-acyl sphing-4-enyl phosphocholine. Since these molecules are easily separated by HPLC, removal of these substances can explain the increased recovery of bioassayable PAF after HPLC. A recent report by Benveniste and co-workers (39) has shown the association of both PAF and lyso-PAF to blood lipoproteins in normal volunteers. These data are consistent with our results since both control and nonseptic individuals had assayable PAF in whole blood, but not associated with platelets. In contrast, septic patients showed a reduced number of freely accessible receptors and measurable amounts of platelet-associated PAF. All these findings can explain recent discrepancies regarding the demonstration of PAF in biological samples and indicate that measurement of PAF at the target level could be related to the biological actions of PAF.

The binding of PAF to membrane receptors has been shown in platelets $(20,40-42)$, polymorphonuclear leukocytes (29), and pulmonary tissue (43) from man and other animal species, and occupancy of PAF-receptors has been found in a group of asthmatic patients after antigen challenge (44). Our findings on kinetics and number of binding sites are similar to those reported by Kloprogge and Akkerman (20) but different from our own data obtained in platelets isolated by centrifugation (40), instead of gel filtration as in the present study. We selected the latter procedure to separate platelets because it is fast and causes minimal damage to the platelets. These requirements seem mandatory when trying to associate changes observed in ex vivo samples with changing clinical conditions. Metabolic conversion of PAF to alkyl-acyl-derivatives after interaction with the PAF-receptor has been reported in rabbit platelets (45), but not in human platelets $(20,46,47)$. Our findings show a low conversion rate of PAF to alkyl-acyl-glycero-phosphocholine even after long periods of incubation and this supports our method of isolating native PAF from ex vivo platelet samples. As to the origin of the high amounts of PAF reported in this study, several sources could be involved: endothelial cells $(48,49)$, mononuclear and polymorphonuclear phagocytes $(50,51)$, platelets themselves (52), and bacteria (53). In fact, generation of PAF from all of these sources has been described and stimulation of these cells can occur during phagocytosis of bacteria or as a consequence of interaction with endotoxin. The finding of a reduced number of accessible high affinity binding sites in a patient with myocardial infarction can be explained by the recent report by Annable and co-workers (54) showing the generation of PAF from ischemic baboon myocardium under conditions of massive necrosis. Our findings showing high amounts of PAF even in patients with gram-positive septicemia suggest that endotoxin is not the only trigger for PAF release under these clinical conditions and suggest a widespread role for PAF in cell to cell communication after tissue injury. On the other hand our data do not rule out the possibility that platelets could be synergistically activated by other mediators, nor the involvement of a cascade of mediators in which PAF is only one of the components.

In summary, our data show the presence of high amounts of PAF associated to one of its targets, under conditions of severe tissue injury. These findings provide a rationale for the use of PAF antagonists in patients with severe shock and multiple organ dysfunction.

\section{Acknowledgments}

This study has been supported by grants from Fondo de Investigaciones Sanitarias, Comision Interministerial de Ciencia y Tecnologia and Fundacion Alvarez de Toledo. M. L. Nieto is a fellow from Fondo de Investigaciones Sanitarias. S. Fernandez-Gallardo and M. A. Gijon are fellows from Fundacion Conchita Rabago.

\section{References}

1. Morrison, D. C., and R. J. Ulevitch. 1978. The effects of bacterial endotoxin on host mediation systems. Am. J. Pathol. 93:527-617. 
2. Heffner, J. E., and R. J. Ulevitch. 1987. The role of platelets in the adult respiratory distress syndrome: culprits or bystanders. $\mathrm{Am}$. Rev. Res. Dis. 153:482-492.

3. Demopoulos, C. A., R. N. Pinckard, and D. J. Hanahan. 1979. Platelet-activating factor. Evidence for 1-O-alkyl-2-acetyl-sn-glycero3-phosphocholine as the active component (a new class of lipid chemical mediators). J. Biol. Chem. 254:9355-9358.

4. Benveniste, J., M. Tence, P. Varenne, J. Bidault, C. Boullet, and J. Polonski. 1979. Semi-synthese et structure proposée du facteur activant les plaquettes (P.A.F). PAF-acether un alkyl ether analogue de la lysophosphatidylcholine. C. R. Hebd. Seances Acad. Sci. 289:19371940.

5. Blank, M. L., F. Snyder, L. W. Byers, B. Brooks, and E. E. Muirhead. 1979. Antihypertensive activity of an alkyl ether analog of phosphatidylcholine. Biochem. Biophys. Res. Commun. 90:11941200.

6. McManus L. M., D. J. Hanahan, C. A. Demopoulos, and R. N. Pinckard. 1980. Pathobiology of the intravenous infusion of acetyl glyceryl ether phosphorylcholine (AGEPC) a synthetic platelet activating factor (PAF), in the rabbit. J. Immunol. 124:2919-2924.

7. Sanchez Crespo, M., F. Alonso, P. Iñarrea, V. Alvarez, and J. Egido. 1982. Vascular actions of synthetic paf-acether (a synthetic platelet activating factor) in the rat: evidence for a platelet independent mechanism. Immunopharmacology. 4:173-185.

8. Bessin P., J. Bonnet, D. Apfell, C. Soulard, L. Desgroux, J. Pelas, and J. Benveniste. 1983. Acute circulatory collapse caused by plateletactivating factor (paf-acether) in dogs. Eur. J. Pharmacol. 86:406-412.

9. Iñarrea, P., J. Gomez-Cambronero, J. Pascual, M. C. Ponte, L. Hernando, and M. Sanchez Crespo. 1985. Synthesis of PAF and blood volume changes in gram-negative sepsis. Immunopharmacology. 9:45-52.

10. Doebber, T. W., M. S. Wu, J. C. Robbins, B. M. Choy, M. N. Chang, and T. W. Shen. 1985. Platelet-activating factor involvement in endotoxin-induced hypotension in rats: studies with PAF-receptor antagonist kadsurenone. Biochem. Biophys. Res. Commun. 127:799808.

11. Chang S-W., C. O. Feddersen, P. M. Henson, and N. F. Voelkel. 1987. Platelet-activating factor mediates hemodynamic changes and lung injury in endotoxin treated rats. J. Clin. Invest. 79:14981508 .

12. Terashita, Z., Y. Imura, S. Nishikawa, and S. Sumida. 1985. Is platelet-activating factor a mediator of endotoxic shock? Eur. J. Pharmacol. 109:257-261.

13. Adnot, S., J. Lefort, V. Lagente, P. Braquet, and B. B. Vargaftig. 1986. Interference of BN 52021, a paf-acether antagonist, with endotoxin-induced hypotension in the guinea pig. Pharmacol. Res. Commun. 18:197-200.

14. Beijer, L., J. Botting, A. O. Oyekan, C. P. Page, and R. Rylander. 1987. The involvement of platelet activating factor in endotoxin-induced pulmonary platelet recruitment in the guinea-pig. $B r . J$ Pharmacol. 92:803-808.

15. Heffner, J. E., S. A. Shoemaker, E. M. Canham, M. Patel, I. F. McMurtry, H. G. Morris, and J. E. Repine. 1983. Acetyl glyceryl ether phosphorylcholine-stimulated human platelets cause pulmonary hypertension and edema in isolated rabbit lungs: role of thromboxane $A_{2}$ J. Clin. Invest. 71:351-357.

16. Vargaftig, B. B., J. Lefort, M. Chignard, and J. Benveniste. 1980. Platelet-activating factor induces a platelet-dependent bronchoconstriction unrelated to the formation of prostaglandin derivatives. Eur. J. Pharmacol. 65:185-192.

17. Jackson, C. V., W. A. Schumacher, S. L. Kunkel, E. M. Driscoll, and B. R. Luchessi. 1986. Platelet-activating factor and the release of a platelet-derived coronary artery vasodilator substance in the canine. Circ. Res. 58:218-229.

18. Weinstein, M. P., L. Barth Reller, J. R. Murphy, and K. A Lichtenstein. 1983. The clinical significance of positive blood cultures: a comprehensive analysis of 500 episodes of bacteremia and fungemia in adults. I. Laboratory and epidemiologic observations. Rev. Infect. Dis. 5:35-53.

19. Bone, R. C., C. J. Fisher, T. P. Clemmer, G. J. Slotman, C. A Metz, and R. Balk. 1987. A controlled clinical trial of high-dose methylprednisolone in the treatment of severe sepsis and septic shock. $N$. Engl. J. Med. 317:653-658.

20. Kloprogge, E., and J. W. N. Akkerman. 1984. Binding kinetics of paf-acether (1-O-alkyl-2-acetyl-sn-glycero-3-phosphocholine) to intact human platelets. Biochem. J. 223:901-909.

21. Scatchard, G. 1949. The attractions of proteins for molecules and ions. Ann. NY Acad. Sci. 51:660-672.

22. Bligh, E. G., and W. J. Dyer. 1959. A rapid method of total lipid extraction and purification. Can. J. Biochem. Physiol. 37:911-917.

23. Henson, P. M. 1976. Activation and desensitization of platelets by platelet-activating factor derived from IgE-sensitized basophils. $J$. Exp. Med. 143:937-952.

24. Caramelo, C., S. Fernandez-Gallardo, D. Marin-Cao, P. Iñarrea, J. C. Santos, J. M. Lopez Novoa, and M. Sanchez Crespo. 1984. Presence of platelet-activating factor in blood from human and experimental animals. Its absence in anephric individuals. Biochem. Biophys. Res. Commun. 120:789-796.

25. Nieto, M. L., S. Velasco, and M. Sanchez Crespo. 1988. Biosynthesis of platelet-activating factor by human polymorphonuclear leukocytes: involvement of the cholinephosphotransferase pathway in response to the phorbol esters. J. Biol. Chem. 262:2217-2222.

26. Blank, M. L., and F. Snyder. 1983. Improved high-performance liquid chromatographic method for isolation of platelet-activating factor from other phospholipids. J. Chromatogr. 273:415-420.

27. Patton, G. M., J. M. Fasulo, and S. Robins. 1982. Separation of phospholipids and individual molecular especies by high-performance liquid chromatography. J. Lipid Res. 23:190-196.

28. Jackson, E. M., G. E. Mott, C. Hoppens, L. M. McManus, S. T. Weintraub, J. C. Ludwig, and R. N. Pinckard. 1984. High performance liquid chromatography of platelet-activating factors. J. Lipid Res. 25:753-757.

29. Valone, F. H., and E. J. Goetzl. 1983. Specific binding by human polymorphonuclear leukocytes of the immunological mediator 1-O-hexadecyl/octadecyl-2-acetyl-sn-glycero-3-phosphocholine. Immunology. 48:141-148.

30. Pinckard, R. N., R. S. Farr, and D. J. Hanahan. 1979. Physiochemical and functional identification of rabbit platelet activating factor (PAF) released in vivo during IgE anaphylaxis with PAF released in vitro from IgE-sensitized basophils. J. Immunol. 123:1847-1857.

31. Camussi, G., C. Tetta, M. C. Deregibus, F. Bussolino, and A. Vercellone. 1982. Platelet-activating factor (PAF) in experimentally induced rabbit acute serum sickness: role of basophil derived PAF in immune complex deposition. J. Immunol. 128:86-94.

32. Iñarrea, P., F. Alonso, and M. Sanchez Crespo. 1983. Plateletactivating factor an effector substance of the vasopermeability changes induced by the infusion of immune aggregates in the mouse. Immunopharmacology. 6:7-14.

33. Villamediana, L. M., E. Sanz, S. Fernandez-Gallardo, C. Caramelo, M. Sanchez Crespo, P. Braquet, and J. M. Lopez Novoa. 1986. Effects of the platelet-activating factor antagonist BN 52021 on the hemodynamics of rats with experimental cirrhosis of the liver. Life Sci. 39:201-205.

34. Grandel, K. E., R. S. Farr, A. A. Wanderer, T. C. Eisenstadt, and S. J. Wasserman. 1985. Association of platelet-activating factor with primary acquired cold urticaria. N. Engl. J. Med. 313:404-409.

35. Caramelo, C., S. Fernandez-Gallardo, J. C. Santos, P. Iñarrea, M. Sanchez Crespo, J. M. Lopez Novoa, and L. Hernando. 1987. Increased levels of platelet-activating factor in blood from patients with cirrhosis of the liver. Eur. J. Clin. Invest. 17:7-11.

36. Sanchez Crespo, M., P. Iñarrea, V. Alvarez Chiva, F. Alonso, J. Egido, and L. Hernando. 1983. Presence in normal human urine of a hypotensive and platelet activating phospholipid. Am. J. Physiol. 244:F706-F711. 
37. Miwa M., C. Hill, R. Kumar, J. Sugatani, M. L. Olson, and D. J. Hanahan. 1987. Occurrence of an endogenous inhibitor of platelet activating factor in rat liver. J. Biol. Chem. 262:527-530.

38. Nakayama, R., K. Yasuda, and K. Saito. 1987. Existence of endogenous inhibitors of platelet-activating factor (PAF) with PAF in rat uterus. J. Biol. Chem. 262:13174-13179.

39. Benveniste, J., D. Nunez, P. Duriez, R. Korth, J. Bidault, and J. C. Frutchard. 1988. Preformed PAF-acether and lyso PAF-acether are bound to blood lipoproteins. FEBS (Fed. Eur. Biochem. Soc.) Lett. 226:371-376.

40. Valone, F. H., E. Coles, V. R. Reinhold, and E. J. Goetzl. 1982. Specific binding of phospholipid platelet-activating factor by human platelets. J. Immunol. 129:1637-1641.

41. Iñarrea, P., J. Gomez-Cambronero, M. L. Nieto, and M. Sanchez Crespo. 1984. Characteristics of the binding of platelet-activating factor to platelets from different animal species. Eur. J. Pharmacol. 105:309-315.

42. Valone, F. K. 1984. Isolation of a human platelet membrane protein which binds the platelet-activating factor 1-O-hexadecyl-2 acetyl-sn-glycero-3-phosphorylcholine. Immunology. 52:169-175.

43. Hwang, S. B., M. H. Lam, and T. Y. Shen. 1985. Specific binding sites for platelet activating factor in human lung tissues. Biochem. Biophys. Res. Commun. 128:972-979.

44. Akkerman, J. W. N., E. Kloprogge, and P. B. L. Bruynzeel. 1987. Platelets play a role in the immediate allergen-induced bronchoconstrictive reaction in the asthmatics. Thromb. Haemostasis. 58:21. (Abstr.)

45. Pieroni, G., and D. J. Hanahan. 1983. Metabolic behavior of acetyl glyceryl ether phosphorylcholine on interaction with rabbit platelets. Arch. Biochem. Biophys. 224:485-493.

46. Alam, I., J. B. Smith, and M. J. Silver. 1983. Metabolism of platelet-activating factor by blood platelets and plasma. Lipids. 18:534-538.

47. Valone, F. H. 1985. Inhibition of binding of the platelet-activating factor AGEPC to platelets by the AGEPC analog rac-3-(N-noctadecylcarbamoyloxy)-2-methoxypropyl-2-thiazolioethyl phosphate (CV-3988). Biochem. Biophys. Res. Commun. 126:502-508.

48. Camussi, G., M. Aglietta, F. Malavasi, C. Tetta, W. Piacibello, F. Sanavio, and F. Bussolino. 1983. The release of platelet-activating factor from human endothelial cells in culture. J. Immunol. 131:2397-2403.

49. McIntyre, T. M., G. A. Zimmerman, K. Satoh, and S. M. Prescott. 1985. Cultured endothelial cells synthesize both platelet-activating factor and prostacyclin in response to histamine, bradykinin and adenosine triphosphate. J. Clin. Invest. 76:271-280.

50. Lotner, G. Z., J. M. Lynch, S. J. Betz, and P. M. Henson. 1980. Human neutrophil derived platelet activating factor. J. Immunol. 124:676-684.

51. Sanchez Crespo, M., F. Alonso, and J. Egido. 1980. Plateletactivating factor in anaphylaxis and phagocytosis. I. Release from human polymorphonuclears and monocytes during stimulation by ionophore A23187 and phagocytosis but not from degranulating basophils. Immunology. 40:645-655.

52. Chignard, M., J. P. LeCouedic, M. Tence, B. B. Vargaftig, and J. Benveniste. 1979. The role of platelet-activating factor in platelet aggregation. Nature (Lond.). 279:799-780.

53. Thomas, Y., Y. Denizot, E. Dassa, C. Boullet, and J. Benveniste. 1986. Synthese du paf-acether par E. coli K12. C. R. Hebd. Seances Acad. Sci. 303:699-702.

54. Annable, C. R., L. M. McManus, K. D. Carey, and R. N. Pinckard. 1987. Isolation of platelet-activating factor (PAF) from ischemic baboon myocardium. Fed. Proc. 46:1271. (Abstr.) 